\title{
Korean Medication Algorithm for Depressive Disorder 2021, Fourth Revision: An Executive Summary
}

\author{
Jeong Seok Seo", Won-Myong Bahk², Young Sup Woo², Young-Min Park ${ }^{3}$, Won Kim, Jong-Hyun Jeong ${ }^{2}$, \\ Se-Hoon Shim ${ }^{5}$, Jung Goo Lee ${ }^{6}$, Seung-Ho Jang ${ }^{7}$, Chan-Mo Yang ${ }^{7}$, Sheng-Min Wang ${ }^{2}$, Myung Hun Jung ${ }^{8}$, \\ Hyung Mo Sung ${ }^{9}$, IL Han Choo ${ }^{10,11}$, Bo-Hyun Yoon ${ }^{12}$, Sang-Yeol Lee ${ }^{7}$, Duk-In Jon ${ }^{8}$, Kyung Joon Min ${ }^{1}$ \\ ${ }^{1}$ Department of Psychiatry, College of Medicine, Chung-Ang University, Seoul, ${ }^{2}$ Department of Psychiatry, College of Medicine, The Catholic \\ University of Korea, Seoul, ${ }^{3}$ Department of Psychiatry, Ilsan Paik Hospital, Inje University College of Medicine, Goyang, ${ }^{4}$ Department of Psychiatry, \\ Sanggye Paik Hospital, Inje University College of Medicine, Seoul, ${ }^{5}$ Department of Psychiatry, Soonchunhyang University Cheonan Hospital, \\ College of Medicine, Soonchunhyang University, Cheonan, ${ }^{6}$ Department of Psychiatry, Haeundae Paik Hospital, Inje University College of Medicine, \\ Busan, 'Department of Psychiatry, Wonkwang University Hospital, School of Medicine, Wonkwang University, Iksan, ${ }^{8}$ Department of Psychiatry, \\ Hallym University Sacred Heart Hospital, Hallym University College of Medicine, Anyang, ${ }^{9}$ Department of Psychiatry, Soonchunhyang University \\ Gumi Hospital, College of Medicine, Soonchunhyang University, Gumi, ${ }^{10}$ Department of Neuropsychiatry, College of Medicine, Chosun University, \\ ${ }^{11}$ Department of Psychiatry, Chosun University Hospital, Gwangju, ${ }^{12}$ Department of Psychiatry, Naju National Hospital, Naju, Korea
}

Objective: In the 19 years since the Korean College of Neuropsychopharmacology and the Korean Society for Affective Disorders developed the Korean Medication Algorithm Project for Depressive Disorder (KMAP-DD) in 2002, four revisions have been conducted.

Methods: To increase survey efficiency in this revision, to cover the general clinical practice, and to compare the results with previous KMAP-DD series, the overall structure of the questionnaire was maintained. The six sections of the questionnaire were as follows: 1) pharmacological treatment strategies for major depressive disorder (MDD) with/without psychotic features; 2) pharmacological treatment strategies for persistent depressive disorder and other depressive disorder subtypes; 3) consensus for treatment-resistant depression; 4) the choice of an antidepressant in the context of safety, adverse effects, and comorbid physical illnesses; 5) treatment strategies for special populations (children/adolescents, elderly, and women); and 6) non-pharmacological biological therapies. Recommended first-, second-, and third-line strategies were derived statistically.

Results: There has been little change in the four years since KMAP-DD 2017 due to the lack of newly introduced drug or treatment strategies. However, shortened waiting time between the initial and subsequent treatments, increased preference for atypical antipsychotics (AAPs), especially aripiprazole, and combination strategies with AAPs yield an active and somewhat aggressive treatment trend in Korea.

Conclusion: We expect KMAP-DD to provide clinicians with useful information about the specific strategies and medications appropriate for treating patients with MDD by bridging the gap between clinical real practice and the evidence-based world.

KEY WORDS: Algorithm; Depressive disorder; Guideline; Pharmacotherapy.

\section{INTRODUCTION}

Nineteen years have passed since the first Korean

Received: August 1, 2021 / Accepted: August 11, 2021

Address for correspondence: Won-Myong Bahk

Department of Psychiatry, Yeouido St. Mary's Hospital, College of

Medicine, The Catholic University of Korea, 10 63-ro,

Yeongdeungpo-gu, Seoul 07345, Korea

E-mail: wmbahk@catholic.ac.kr

ORCID: https://orcid.org/0000-0002-0156-2510
Medication Algorithm Project for Depressive Disorder (KMAP-DD), the expert's consensus guideline with clinical evidence on the treatment of depressive disorder, was developed in 2002 [1]. Since then, three revisions have been conducted by the KMAP-DD executive committee within the Korean Society for Affective Disorders (KSAD) and the Korean College of Neuropsychopharmacology (KCNP): KMAP-DD 2006 [2], KMAP-DD 2012 [3], and KMAP-DD 2017 [4].

@) This is an Open-Access article distributed under the terms of the Creative Commons Attribution Non-Commercial License (http://creativecommons.org/licenses/by-nc/4.0) which permits unrestricted non-commercial use, distribution, and reproduction in any medium, provided the original work is properly cited. 
Because depressive disorder is a heterogeneous disorder that has various symptoms, clinical courses, and outcomes, the KMAP-DD executive committee conducted a fourth revision in 2021 to assist clinicians with decisions on proper treatment strategies, to standardize the quality of pharmacological treatments as the definitive clinical guideline [5], and to reflect changes that have been made for several years in pharmacological practice in Korea.

We summarized the results of the fourth revision of
Korean experts' opinions on the pharmacological treatment of patients with depressive disorder and compared the 4th revision results to those of the previous KMAP-DD, from 2017, 2012, and 2006; KMAP-DD 2002 was excluded due to questionnaire format and differences in the lists of antidepressants (ADs) and atypical antipsychotics (AAPs).

\section{METHODS}

The overall study design and method used in previous

Table 1. Comparison among the first (2006), second (2012), third (2017), and fourth (2021) revisions of the KMAP-DD

\begin{tabular}{|c|c|c|c|c|}
\hline & First revision in 2006 & Second revision in 2012 & Third revision in 2017 & Fourth revision in 2021 \\
\hline Depressive episode & $\begin{array}{l}\text { Mild } \\
\text { Moderate } \\
\text { Non-psychotic severe } \\
\text { Psychotic severe }\end{array}$ & $\begin{array}{l}\text { Mild to moderate } \\
\text { Non-psychotic severe } \\
\text { Psychotic severe }\end{array}$ & Same as 2012 & Same as 2017 \\
\hline $\begin{array}{l}\text { AD dosage and } \\
\text { duration of } \\
\text { treatment }\end{array}$ & Present & Deletion & $\begin{array}{l}\text { Change: duration of initial } \\
\text { treatment and number of } \\
\text { choosing } A D \text { as initial } \\
\text { treatment }\end{array}$ & Same as 2017 \\
\hline Subtype & $\begin{array}{l}\text { Dysthymia } \\
\text { Minor depressive disorder } \\
\text { Atypical features } \\
\text { Melancholic features. }\end{array}$ & $\begin{array}{l}\text { Dysthymia } \\
\text { Minor depressive disorder } \\
\text { Atypical features } \\
\text { Melancholic features } \\
\text { Seasonal pattern }\end{array}$ & $\begin{array}{l}\text { Dysthymia } \\
\text { Minor depressive disorder } \\
\text { Atypical features } \\
\text { Melancholic features } \\
\text { Seasonal pattern } \\
\text { Mixed features } \\
\text { Anxious distress }\end{array}$ & $\begin{array}{l}\text { PDD (Dysthymia) } \\
\text { Atypical features } \\
\text { Melancholic features } \\
\text { Seasonal pattern } \\
\text { Mixed features } \\
\text { Anxious distress }\end{array}$ \\
\hline $\begin{array}{l}\text { Comorbid physical } \\
\text { illness }\end{array}$ & Absent & Newly added & $\begin{array}{l}\text { DM } \\
\text { Thyroid disease } \\
\text { Liver disease } \\
\text { Renal disease }\end{array}$ & $\begin{array}{l}\text { DM } \\
\text { Thyroid disease } \\
\text { Liver disease } \\
\text { Renal disease } \\
\text { Hypertension } \\
\text { Seizure disorder } \\
\text { Cardiovascular disease } \\
\text { Parkinson's disease } \\
\text { Arrythmia } \\
\text { Chronic pain (fibromyalgia, etc.) }\end{array}$ \\
\hline Special population & Child only & $\begin{array}{l}\text { Child and adolescent } \\
\text { Elderly } \\
\text { Women }\end{array}$ & Same as 2012 & $\begin{array}{l}\text { Child (up to primary school) } \\
\text { Adolescent (up to high school) } \\
\text { Elderly } \\
\text { Women }\end{array}$ \\
\hline $\begin{array}{l}\text { Non-pharmacologic } \\
\text { al biological } \\
\text { therapy }\end{array}$ & ECT only & $\begin{array}{l}\text { Including TMS } \\
\text { Light therapy nutritional } \\
\text { therapy, sleep } \\
\text { deprivation, VNS, DBS as } \\
\text { well as ECT }\end{array}$ & Same as 2012 & $\begin{array}{l}\text { ECT } \\
\text { rTMS } \\
\text { VNS } \\
\text { DBS } \\
\text { Light therapy } \\
\text { Nutritional therapy } \\
\text { tDCS }\end{array}$ \\
\hline $\begin{array}{l}\text { Response rate of } \\
\text { review committee }\end{array}$ & $66.3 \%(67 / 101)$ & $54.5 \%(67 / 123)$ & $54.9 \%(79 / 144)$ & $\begin{array}{l}68.5 \%(98 / 143) \\
\text { (adult 67.0\% [65/97], } \\
\text { child/adolescent 71.7\%, [33/46]) }\end{array}$ \\
\hline
\end{tabular}

KMAP-DD, Korean Medication Algorithm for Depressive Disorder; AD, antidepressant; DBS, deep brain stimulation; DM, diabetes mellitus; ECT, electroconvulsive therapy; PDD, persistent depressive disorder; rTMS, repetitive transcranial magnetic stimulation; $t D C S$, transcranial direct current stimulation; VNS, vagal nerve stimulation. 
revisions were maintained in this revision for the comparison across the KMAP-DD series. To obtain the experts' consensus, the executive committee composed a review committee, and the review committee completed the questionnaire (Table 1).

\section{Review Committee}

The composition criteria and qualifications of the review committee were similar to those of KMAP-DD 2012 and 2017. We recruited 143 Korean psychiatrists (97 adult psychiatrists and 46 child/adolescent psychiatrists) who were lifelong members of KCNP and KSAD, had more than 15 years of clinical experience in the field of psychiatry, and who had each published at least one paper related to mood disorders during the previous year or who have been running a mood clinic in their hospital. Psychiatrists for adult members worked in various clinical settings (university hospitals, $\mathrm{n}=68$; general and mental hospitals, $\mathrm{n}=22$; private psychiatric clinics, $\mathrm{n}=7$ ), and the child/adolescent psychiatrists worked in university hospitals $(n=29)$, general and mental hospitals $(n=6)$, and private psychiatric clinics $(n=11)$. All members of the review committee provided written informed consent for their participation in this survey. Of the 143 psychiatrists, 98 responded to our survey (response rate $=68.5 \%$; adult $=$ $67.0 \%$ [65/97], child/adolescent $=71.7 \%$ [33/46]). Respondents received a predetermined fee for their participation.

\section{Questionnaire}

The questionnaire included six sections and thirty three general questions, including 118 sub-items and 764 options. The six sections of the questionnaire were as follows: 1) pharmacological treatment strategies for mild-to-moderate, severe without psychotic features (non-psychotic severe episode), and severe episode with psychotic features (psychotic severe episode) (first to third step); 2) pharmacological treatment strategies for persistent depressive disorder (PDD) and depressive disorder subtypes; 3) consensus for treatment-resistant depression; 4) the choice of an antidepressant in the context of safety, adverse effects, and comorbid physical illnesses; 5) treatment strategies for special populations (children/adolescents, elderly, and women); and 6) non-pharmacological biological therapies (electroconvulsive therapy, ECT; repetitive transcranial magnetic stimulation, rTMS; etc.). The executive committee decided to exclude fluvoxamine due to lack of usage in Korea and include esketamine (nasal spray), a newer antidepressant approved for treatment-resistant depression (TRD) (Table 2). In this revision, the list of AAPs is the same as in 2017, including amisulpride, aripiprazole, blonanserin, clozapine, olanzapine, paliperidone, quetiapine, risperidone, and ziprasidone.

Unlike previous surveys, children (primary school students and younger) and adolescents (middle and high school students) were investigated separately within the children/adolescents with depression group.

\section{Rating Scale}

The overall rating method was the same as before. Each treatment option was scored on a nine-point scale. Nine indicates extremely appropriate, $7-8$ indicates usually

Table 2. Lists of drugs used in KMAP-DD 2021

\begin{tabular}{ll}
\hline Antidepressant & Agomelatine \\
& Bupropion \\
& Esketamine (nasal spray) ${ }^{a}$ \\
& Mirtazapine \\
& SNRI (desvenlafaxine, duloxetine, milnacipran, venlafaxine) \\
& SSRI (escitalopram, fluoxetine, paroxetine, sertraline) ${ }^{b}$ \\
& Tianeptine \\
& TCA (amitriptyline, clomipramine, imipramine, etc.) \\
& Vortioxetine ${ }^{\mathrm{a}}$ \\
& Carbamazepine, lamotrigine, lithium, valproate \\
Mood stabilizer & Amisulpride, aripiprazole, blonanserin, clozapine, olanzapine, paliperidone, quetiapine, risperidone, ziprasidone \\
Antipsychotics & Typical antipsychotics \\
& Buspirone, mood stabilizer, psychostimulant, thyroid hormone, etc. \\
\hline Augmentation drugs &
\end{tabular}

KMAP-DD, Korean Medication Algorithm for Depressive Disorder; SNRI, serotonin and norepinephrine reuptake inhibitor; SSRI, selective serotonin reuptake inhibitor; TCA, tricyclic antidepressant.

${ }^{a}$ Newly included in $\mathrm{AD}$ lists in this survey. ${ }^{\mathrm{b}}$ Fluvoxamine was deleted in $\mathrm{AD}$ lists. 


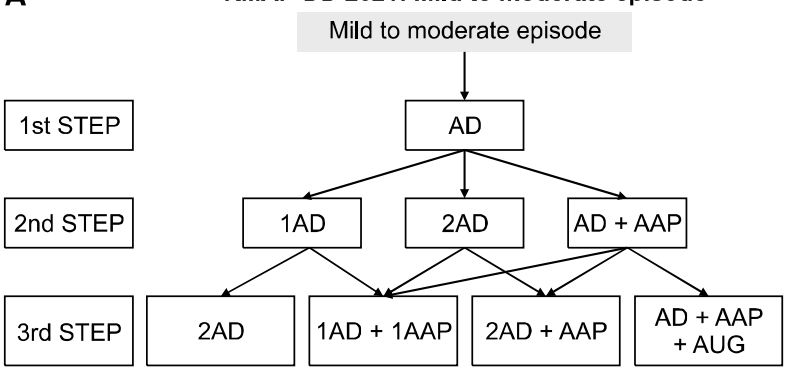

B

KMAP-DD 2021: Severe episode without psychotic features Severe episode without psychotic features

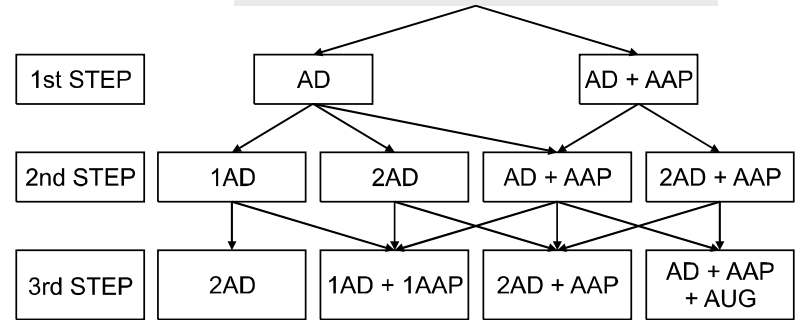

C

KMAP-DD 2021: Severe episode with psychotic features Severe episode with psychotic features

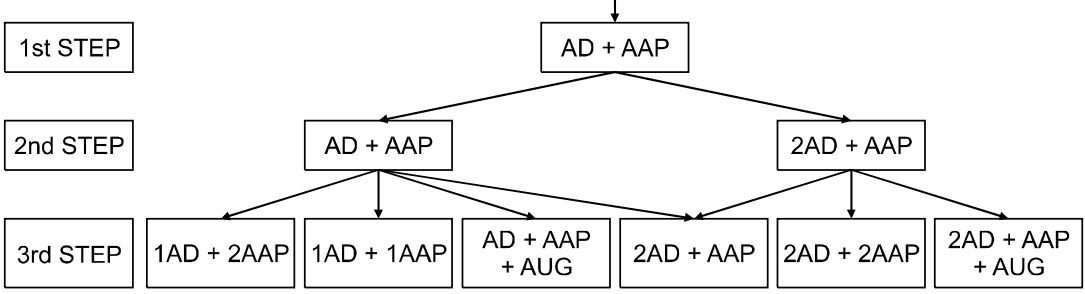

Fig. 1. The Korean Medication Algorithm for Depressive Disorder 2021.

KMAP-DD, Korean Medication Algorithm for Depressive Disorder; AD, antidepressants; AAP, atypical antipsychotics; AUG, augmenting agents.

appropriate, 4-6 indicates ambivalence about its appropriateness, $2-3$ indicates usually inappropriate (a treatment the clinician would rarely use), and 1 indicates extremely inappropriate (a treatment the clinician would never use). Some questions had a numeric response instead of a rating. For example, "How long do you wait before switching ongoing AD or AAP?"

\section{Data Analysis and Decision of Preference and Categories}

Means and $95 \%$ confidence intervals $(\mathrm{Cl})$ of each question or option were calculated. We divided them into three categories according to the lowest score of $95 \% \mathrm{Cl}$ : firstline/preferred treatment, $\geq 6.5$; second-line/reasonable treatment, $<6.5$ and $\geq 3.5$; and third-line/inappropriate treatment, $<3.5$. Treatment of choice (TOC) was defined as an option that was rated at 9 points by $50 \%$ or more of the experts.

A chi-square test was used to confirm the presence or absence of consensus on each option/question. No significant difference between categories indicated lack of consensus.

The SPSS 15.0 software package (SPSS Inc., Chicago, IL, USA) was used for the analyses of preference rankings and multiple responses.

\section{Development of Treatment Guidelines and Algorithms}

After the advisory committee and the executive committee discussed these results and reviewed the clinical evidence, considering Korean clinical situations, the executive committee drew up the fourth revised KMAP-DD algorithms (Fig. 1) and distributed KMAP-DD 2021 to psychiatrists and related experts in Korea.

\section{Ethics}

The present study was conducted according to the Declaration of Helsinki. The study protocol was approved by the Institutional Review or Ethics Committee at Wonkwang University (approved number: WKUH 2020-12-012). The revision process was funded entirely by KCNP and KSAD without external financial support.

\section{RESULTS}

\section{Treatment Strategy for Acute Depression with or Without Psychotic Features (Table 3)}

\section{Initial step strategies for depressive episode}

For mild-to-moderate depressive episodes, AD monotherapy $(95 \% \mathrm{Cl} 8.47-8.84)$ was recommended as the TOC. For non-psychotic severe episodes, AD mono- 


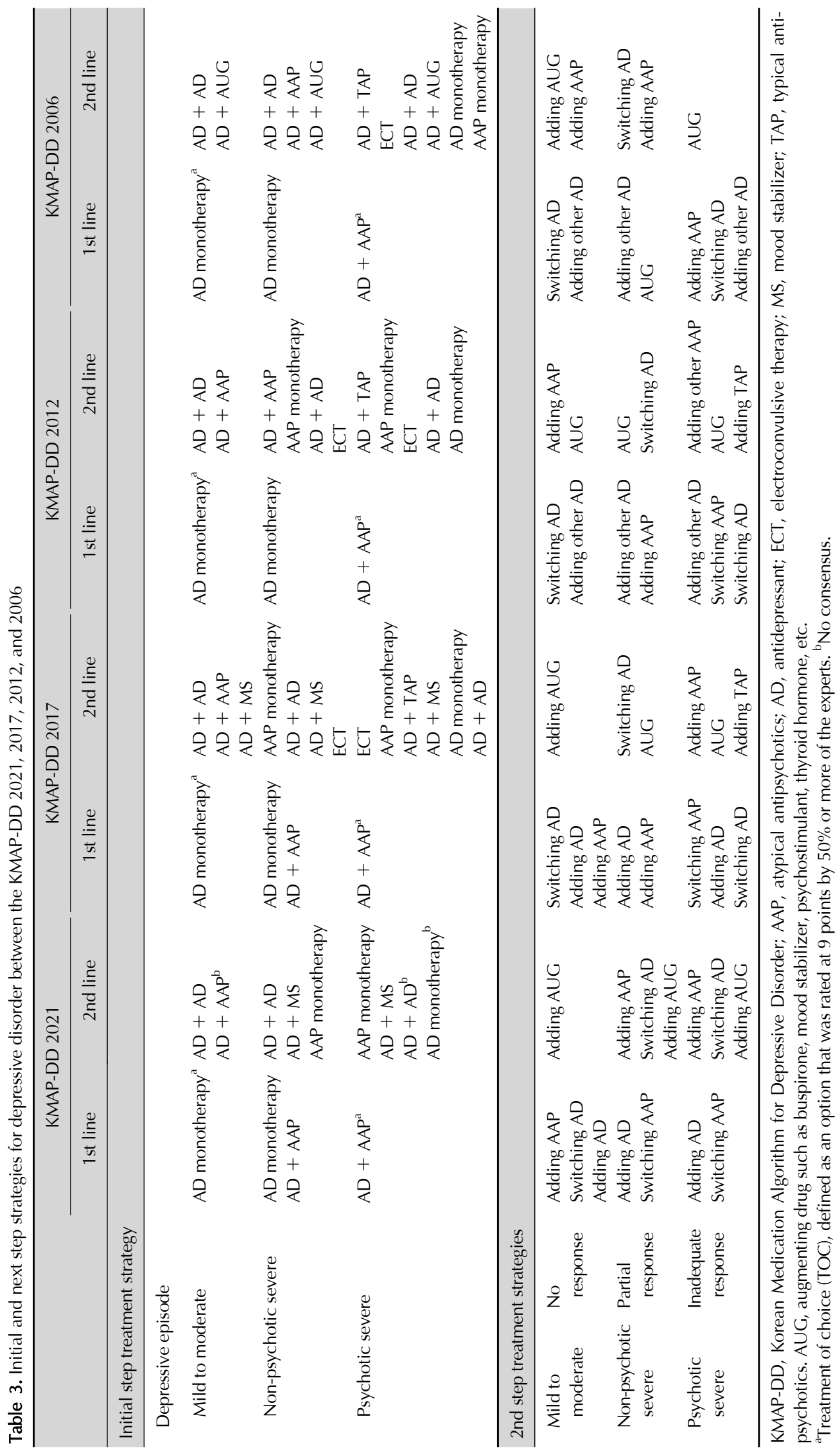


therapy and $A D+A A P$ were the preferred first-line strategies (Table 4). For psychotic severe episodes, the AD + AAP combination was the TOC in all four KMAP-DD revisions.

\section{Second-step strategies when initial strategies yield no or partial response}

When the patient is unresponsive to the initial AD monotherapy, adding $\mathrm{AD}$ or $\mathrm{AAP}$ and switching $\mathrm{AD}$ were preferred. With a partial response rather than 'no response' to $A D$ monotherapy, adding $A D$ or $A A P$ was preferred. When unresponsive to the initial AD + AAP combination, switching $\mathrm{AAP}$ or $\mathrm{AD}$ and adding $\mathrm{AD}$ were preferred. With partial response to the initial $A D+A A P$, adding $A D$ and switching AAP were preferred.

In general, changing ADs occurred among SSRIs, SNRIs, and mirtazapine, and adding ADs occurred among SSRIs, SNRIs, mirtazapine, bupropion, agomelatine, and vortioxetine, depending on the drug being used. Changing or adding AAPs occurred among aripiprazole, quetiapine, and olanzapine in the same way.

\section{Third-step strategies when second-step strategies have no or partial response}

When there is inadequate response to the second-step treatment, adding another AAP or AD or changing AAP or $\mathrm{AD}$ were recommended. Adding augmentation drugs, such as buspirone, mood stabilizer, psychostimulant, and thyroid hormone, was preferred when there was an inadequate response to adding AAP to AD monotherapy for non-psychotic depression and when there was an inadequate response to either adding $\mathrm{AD}$ to an $\mathrm{AD}+\mathrm{AAP}$ combination (2ADs + AAP) or switching or adding AAP to ongoing $\mathrm{AD}+\mathrm{AAP}$ for psychotic depression.

\section{AD Choices}

\section{Preferred $A D$ for initial treatment}

For mild-to-moderate depressive episodes, escitalopram $(95 \% \mathrm{Cl} 8.3-8.7)$ was the TOC, and sertraline, desvenlafaxine, fluoxetine, venlafaxine, vortioxetine, duloxetine, mirtazapine, and paroxetine were recommended as first-line ADs. For non-psychotic severe episodes, escitalopram $(95 \% \mathrm{Cl} 8.1-8.5)$ was the TOC, and desvenlafaxine, venlafaxine, sertraline, mirtazapine, fluoxetine, duloxetine, paroxetine, and vortioxetine were the first-line ADs. For psychotic severe episodes, escitalopram $(95 \% \mathrm{Cl}$ $8.1-8.5)$ was the TOC, and venlafaxine, desvenlafaxine, sertraline, mirtazapine, fluoxetine, paroxetine, and duloxetine were recommended as the first-line ADs.

\section{$A D$ choice considering adverse effects, safety, or comorbid physical illness}

We asked the experts to choose three ADs when con-

Table 4. Comparison of preference of antipsychotics in the Korean Medication Algorithm for Depressive Disorder

\begin{tabular}{|c|c|c|c|c|c|c|c|}
\hline \multirow{2}{*}{$\begin{array}{l}\text { Preference of } \\
\text { atypical } \\
\text { antipsychotics }\end{array}$} & \multicolumn{2}{|c|}{$\begin{array}{c}\text { Fourth revision in } 2021, \\
\text { severe episode }\end{array}$} & \multicolumn{2}{|c|}{$\begin{array}{l}\text { Third revision in } 2017, \\
\text { severe episode }\end{array}$} & \multicolumn{2}{|c|}{$\begin{array}{c}\text { Second revision in 2012, } \\
\text { severe episode }\end{array}$} & \multirow{2}{*}{$\begin{array}{l}\text { First revision } \\
\text { in } 2006\end{array}$} \\
\hline & $\begin{array}{l}\text { Without } \\
\text { psychotic } \\
\text { features }\end{array}$ & $\begin{array}{l}\text { With psychotic } \\
\text { features }\end{array}$ & $\begin{array}{l}\text { Without psychotic } \\
\text { features }\end{array}$ & $\begin{array}{l}\text { With psychotic } \\
\text { features }\end{array}$ & $\begin{array}{l}\text { Without } \\
\text { psychotic } \\
\text { features }\end{array}$ & $\begin{array}{l}\text { With psychotic } \\
\text { features }\end{array}$ & \\
\hline Amisulpride & $4.2(3.7-4.7)$ & $5.7(5.3-6.2)$ & $5.0(4.6-5.5)$ & $6.0(5.6-6.3)$ & $5.5(5.0-5.9)$ & $6.6(6.1-7.0)$ & $5.8(5.3-6.2)$ \\
\hline Aripiprazole & $7.6(7.2-8.0)^{\mathrm{a}}$ & $8.4(8.2-8.6)^{a, b}$ & $8.3(8.2-8.5)^{a, b}$ & $8.3(8.1-8.5)^{\mathrm{a}}$ & $7.9(7.6-8.2)^{a}$ & $7.9(7.6-8.2)^{\mathrm{a}}$ & $6.3(5.8-6.7)$ \\
\hline Blonanserin & $3.9(3.5-4.4)$ & $5.8(5.3-6.2)$ & $4.6(4.2-5.0)$ & $6.1(5.7-6.5)$ & $4.4(3.7-5.1)$ & $5.8(5.1-6.4)$ & - \\
\hline Clozapine & $2.6(2.2-3.1)$ & $4.3(3.8-4.8)$ & $2.7(2.3-3.1)$ & $3.9(3.4-4.3)$ & $2.9(2.4-3.4)$ & $4.1(3.6-4.6)$ & $3.5(3.0-4.0)$ \\
\hline Olanzapine & $5.2(4.6-5.7)^{\mathrm{C}}$ & $7.3(6.9-7.7)^{\mathrm{a}}$ & $6.0(5.6-6.4)$ & $7.3(7.0-7.7)^{\mathrm{a}}$ & $6.6(6.2-7.0)$ & $7.6(7.3-7.9)^{\mathrm{a}}$ & $7.1(6.7-7.5)^{\mathrm{a}}$ \\
\hline Paliperidone & $4.0(3.5-4.6)$ & $6.1(5.6-6.6)$ & $4.5(4.1-5.0)$ & $6.9(5.6-6.5)$ & - & - & - \\
\hline Quetiapine & $6.9(6.4-7.8)$ & $8.0(7.7-8.2)^{a}$ & $7.8(7.6-8.0)^{\mathrm{a}}$ & $7.9(7.7-8.1)^{\mathrm{a}}$ & $7.7(7.4-8.0)^{\mathrm{a}}$ & $8.1(7.8-8.3)^{\mathrm{a}}$ & $7.3(6.9-7.7)^{\mathrm{a}}$ \\
\hline Risperidone & $4.7(4.2-5.2)$ & $6.8(6.4-7.2)$ & $5.3(4.8-5.7)$ & $6.7(6.3-7.1)$ & $6.0(5.5-6.4)$ & $7.3(6.9-7.6)^{\mathrm{a}}$ & $7.3(6.9-7.7)^{\mathrm{a}}$ \\
\hline Ziprasidone & $4.3(3.9-4.8)$ & $5.7(5.3-6.1)$ & $5.1(4.6-5.6)$ & $5.9(5.6-6.3)$ & $5.7(5.2-6.3)$ & $6.5(6.1-6.9)$ & $6.5(6.0-6.9)$ \\
\hline $\begin{array}{l}\text { Typical } \\
\text { antipsychotics }\end{array}$ & $2.3(1.9-2.7)$ & $3.4(2.9-3.9)$ & $2.9(2.5-3.3)$ & $4.0(3.4-4.3)$ & $3.2(2.8-3.6)$ & $4.5(4.0-5.0)$ & $4.8(4.3-5.3)$ \\
\hline
\end{tabular}

Values are presented as mean (95\% confidence interval).

${ }^{\mathrm{a}}$ First-line drug:score of preference is 9 points. ${ }^{\mathrm{b}}$ Treatment of choice (TOC), defined as an option that was rated at 9 points by $50 \%$ or more of the experts. ${ }^{\mathrm{N}}$ No consensus. 
sidering adverse effects, drug safety, and comorbid physical illness, respectively. Considering adverse effects, bupropion, mirtazapine, and vortioxetine were preferred in terms of sexual dysfunction. For sedation and somnolence, bupropion, fluoxetine, and tianeptine; for weight gain, bupropion, fluoxetine, and vortioxetine; for insomnia, mirtazapine, paroxetine, and tricyclic antidepressants (TCAs); for gastrointestinal trouble, mirtazapine, tianeptine and bupropion; and for anticholinergic side effects, escitalopram, agomelatine, and vortioxetine were selected.

Regarding safety issues, for safety accidents such as falling or traffic accidents, bupropion, escitalopram, and fluoxetine; for serotonin syndrome, bupropion, tianeptine, and agomelatine; for orthostatic hypotension, bupropion, escitalopram, and mirtazapine; and for suicidal ideation, mirtazapine, bupropion, and agomelatine were chosen.

Regarding comorbid conditions, for diabetes mellitus (DM), escitalopram, sertraline and bupropion; for thyroid disease, escitalopram, sertraline and fluoxetine; for liver disease, escitalopram, sertraline, and tianeptine; for renal disease, escitalopram, sertraline, and tianeptine; for hypertension, escitalopram, sertraline, and tianeptine; for cardiovascular illness, escitalopram, sertraline, and tianeptine; for seizure disorder, escitalopram, sertraline, and tianeptine; for parkinsonism, escitalopram, sertraline, and bupropion; for arrhythmia, sertraline, escitalopram, and fluoxetine; and for chronic pain, duloxetine, milnacipran, and venlafaxine were preferred.

\section{AAP Choices}

For non-psychotic severe episodes, aripiprazole was only first-line AAP, and quetiapine, olanzapine with no consensus, risperidone, ziprasidone, and amisulpride were recommended as second-line. However, for psychotic severe episodes, aripiprazole was the TOC, and quetiapine and olanzapine were recommended as first-line AAPs (Table 4).

\section{Treatment Duration with Initial AD before Next Strategy}

The reviewers were asked, "How long do you keep using the initial drug until the next strategic change, such as switching or adding, due to lack of efficacy?" With AD monotherapy for mild-to-moderate depressive episodes, their answer was a minimum $2.2 \pm 0.9-$ maximum $6.1 \pm$ 2.3 weeks (no response: $2.2-4.3$ weeks; partial response:
3.3-6.1 weeks). With AD monotherapy for non-psychotic severe episodes, the answer was $1.9 \pm 0.8-5.2 \pm$ 2.2 weeks (no response: $2.2-4.3$ weeks; partial response: $2.9-5.2$ weeks). With AD monotherapy for psychotic severe episodes, their answer was a minimum $1.7 \pm 0.8-$ maximum $4.8 \pm 2.3$ weeks (no response: $1.7-3.3$ weeks; partial response: $2.6-4.8$ weeks).

\section{Treatment Strategies for Persistent Depressive Disorder (Dysthymia) and Subtypes of Depression}

\section{Treatment strategies for PDD}

AD monotherapy with escitalopram was the TOC for PDD. $A D+A A P, A D+A D, A D+$ mood stabilizer (MS), and AAP monotherapy were recommended as second-line strategies.

\section{$A D$ choice according to subtype of depressive episode}

For patients with melancholic features, escitalopram was the TOC and desvenlafaxine, venlafaxine, sertraline, fluoxetine, duloxetine, mirtazapine, paroxetine, vortioxetine, and milnacipran were the first-line ADs. Agomelatine, bupropion, tianeptine, TCA, and esketamine (with no consensus) were second-line ADs.

For atypical features, escitalopram, desvenlafaxine, fluoxetine, sertraline, venlafaxine, duloxetine, vortioxetine, bupropion, paroxetine, milnacipran, and agomelatine were the first-line ADs. Mirtazapine, tianeptine, esketamine, and TCA were second-line ADs.

For seasonal patterns, escitalopram, sertraline, fluoxetine, desvenlafaxine, venlafaxine, duloxetine, paroxetine, vortioxetine, bupropion, and mirtazapine were the first-line ADs. Agomelatine, milnacipran, tianeptine, TCA, and esketamine (with no consensus) were second-line ADs.

\section{Treatment strategies for anxious distress specifiers and mixed features (Table 5)}

For anxious distress, an $\mathrm{AD}+\mathrm{AAP}$ combination or $\mathrm{AD}$ monotherapy were the initial treatment strategies. $A D+$ $A D, A D+M S$, and AAP monotherapy were recommended as the second-line strategies. As an initial AD, escitalopram, fluoxetine, paroxetine, sertraline, duloxetine, venlafaxine, desvenlafaxine, mirtazapine, and vortioxetine were preferred. Aripiprazole, olanzapine, and quetiapine were the first-line AAPs for anxious distress.

For mixed features, $\mathrm{AD}+\mathrm{AAP}$ or $\mathrm{AD}+\mathrm{MS}$ were the 


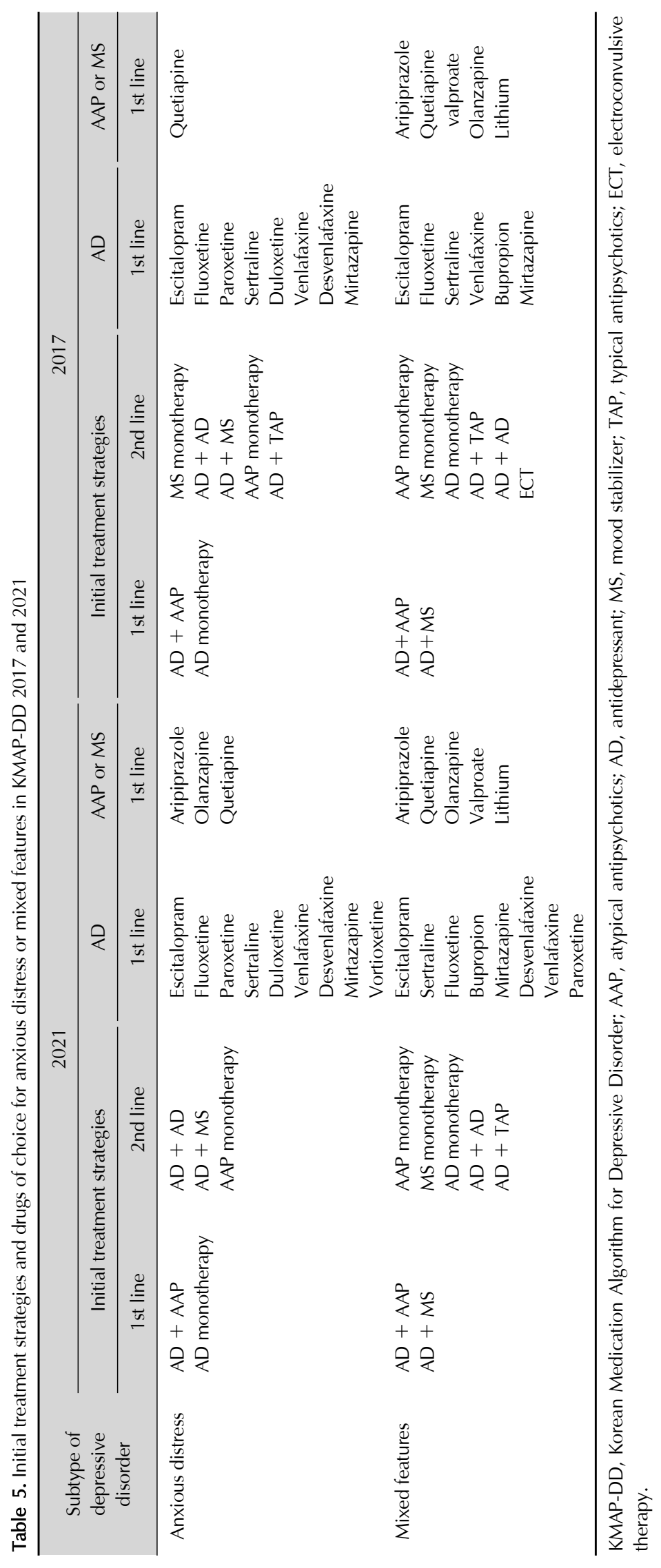


Table 6. Consensus of clinical definition for treatment resistant depression in KMAP-DD 2021

\begin{tabular}{lc}
\hline \multicolumn{1}{c}{ Definition for treatment resistant depression } & Respondent \\
\hline Failure to respond to two AD treatments of separate pharmacological AD class & $13(20.6)$ \\
Failure to respond to three AD treatments of separate pharmacological AD class & $6(9.5)$ \\
Failure to respond to two AD combination treatment & $1(1.6)$ \\
Failure to respond to two AD + one AAP combination treatment of pharmacological AD classes & $28(44.4)$ \\
Failure to respond to two AD + two AAP combination treatment & $12(19.0)$ \\
ECT should be considered for no longer responsive to medications. & $2(3.2)$ \\
Others & $1(1.6)$ \\
Total & $62(100)$ \\
\hline
\end{tabular}

Values are presented as number (\%).

KMAP-DD, Korean Medication Algorithm for Depressive Disorder; AAP, atypical antipsychotic; AD, antidepressant; ECT, electroconvulsive therapy.

first-line strategies, and AAP, MS, or AD monotherapy were recommended as second-line strategies. As preferred ADs, escitalopram, sertraline, fluoxetine, bupropion, mirtazapine, desvenlafaxine, venlafaxine, and paroxetine were recommended, and as AAPs and MSs, aripiprazole, quetiapine, olanzapine, valproate, and lithium were recommended.

\section{Criteria for TRD Chosen by Experts}

Experts were asked about the proper criteria for TRD. The largest number of experts $(44.4 \%)$ chose the criteria for TRD as "Failure to respond to two ADs + one AAP combination treatment". "Failure to respond to two AD treatments of separate pharmacological AD classes" was the second most answered (20.6\%). "Failure to respond to two ADs + two AAPs combination treatment (19.0\%)" and "Failure to respond to three AD treatments of separate pharmacological AD classes (9.5\%)" were in the third and fourth place, respectively. As fifth place, "ECT should be considered for no longer responsive to medications" $(3.2 \%)$, and surprisingly, "Failure to response to a two-AD combination treatment" (1.6\%) was the least preferred (Table 6).

\section{Treatment Strategies for Special Populations (Table 7)}

\section{Depressive disorder in children or adolescents}

For more detailed results, the fourth revision separately surveyed the children (elementary school students) and adolescents (middle and high school students). There is no first-line treatment for disruptive mood dysregulation disorder (DMDD). AAP, or AD monotherapy, and AD + $\mathrm{AAP}$ were recommended as second-line treatment.
Escitalopram and fluoxetine were the first-line ADs, aripiprazole was the TOC, and risperidone and valproate were the first-line AAP and MS, respectively. AD monotherapy was the TOC for mild-to-moderate episodes in children and the first-line treatment strategy for mild-to-moderate episodes in adolescents. AD monotherapy and AD + AAP were the first-line strategies for children and adolescents with non-psychotic severe episodes. AD + AAP were the TOC for children and adolescents with psychotic severe episodes.

As first-line AD, escitalopram and fluoxetine for children, and escitalopram, fluoxetine, and sertraline for adolescents with mild-to-moderate depressive episodes were preferred. For children and adolescents with psychotic or non-psychotic severe episodes, escitalopram, fluoxetine, and sertraline were preferred. Among AAPs, aripiprazole was the TOC for children and adolescents with psychotic severe episodes, and risperidone and quetiapine were the first-line treatment preferences for children with psychotic severe episodes.

\section{Elderly patients with MDD}

AD monotherapy was the TOC for elderly patients with mild-to-moderate depressive episodes. AD monotherapy and $\mathrm{AD}+\mathrm{AAP}$ were the first-line strategies for non-psychotic severe episodes, whereas AD + AAP were the TOC for psychotic severe episodes. Moreover, escitalopram was the TOC for all three types of episodes. Aripiprazole as the TOC and quetiapine as the first-line AAP were recommended for psychotic severe episodes.

\section{Women with depressive disorder}

AD monotherapy was the first-line treatment strategy 


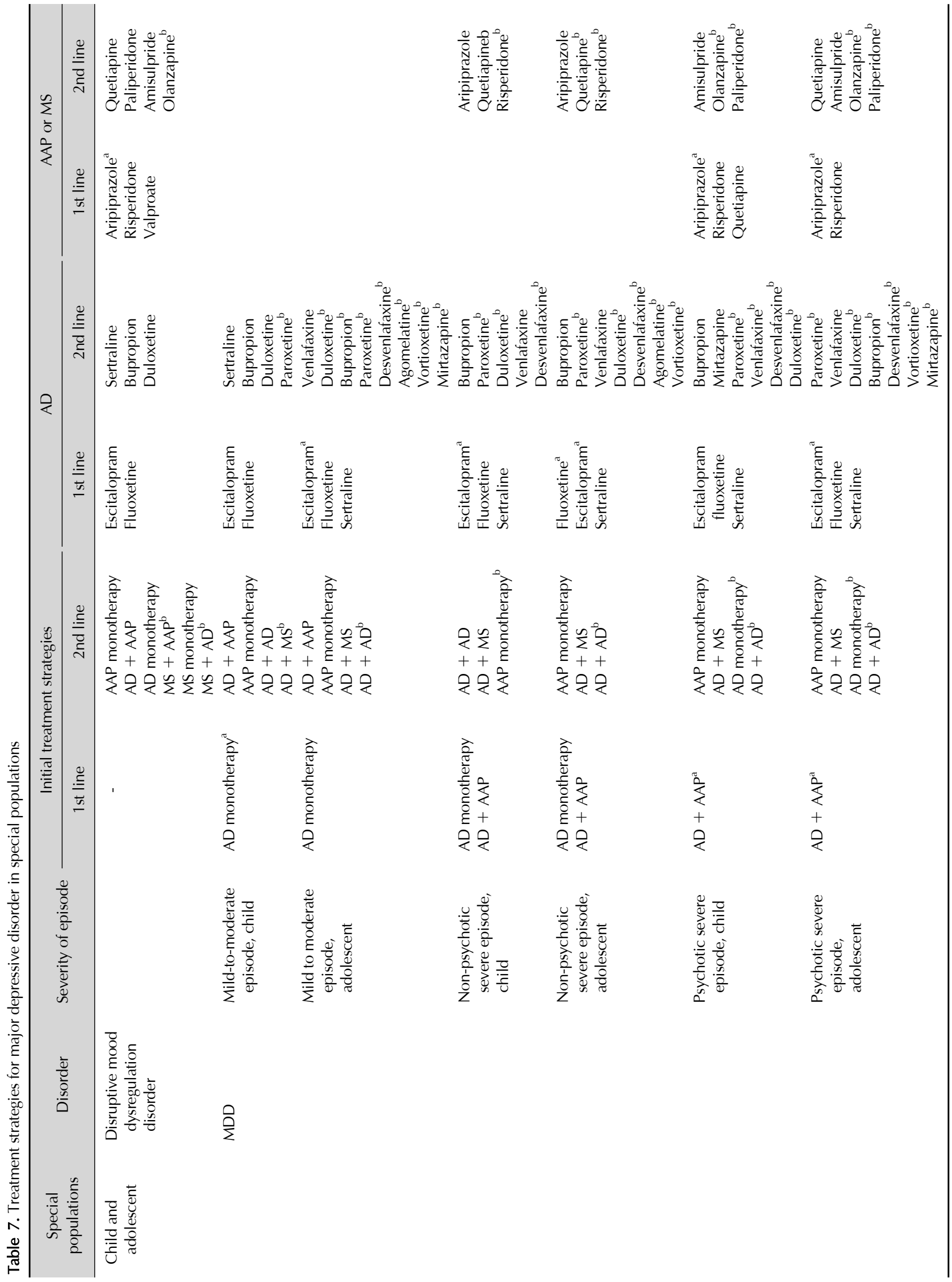




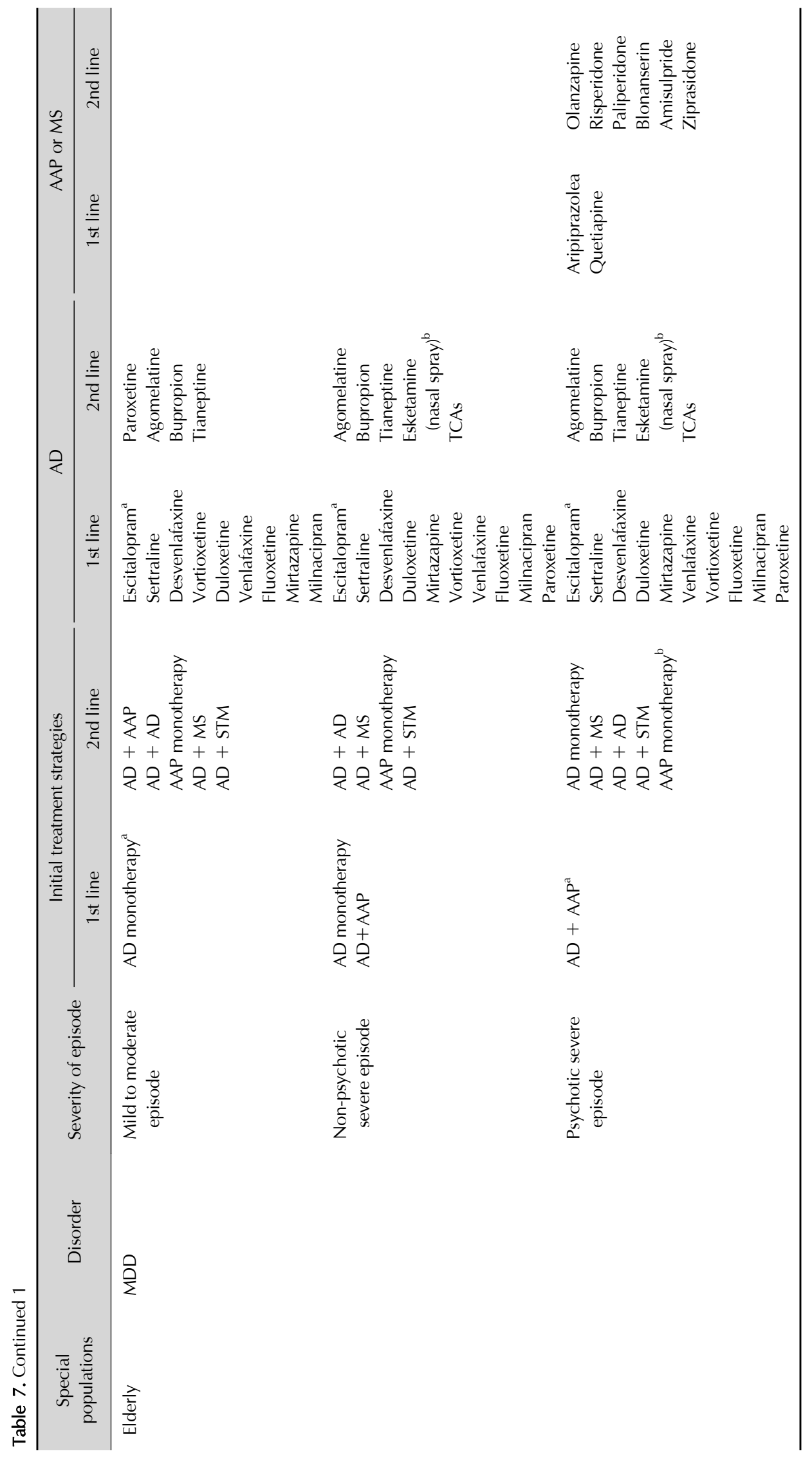




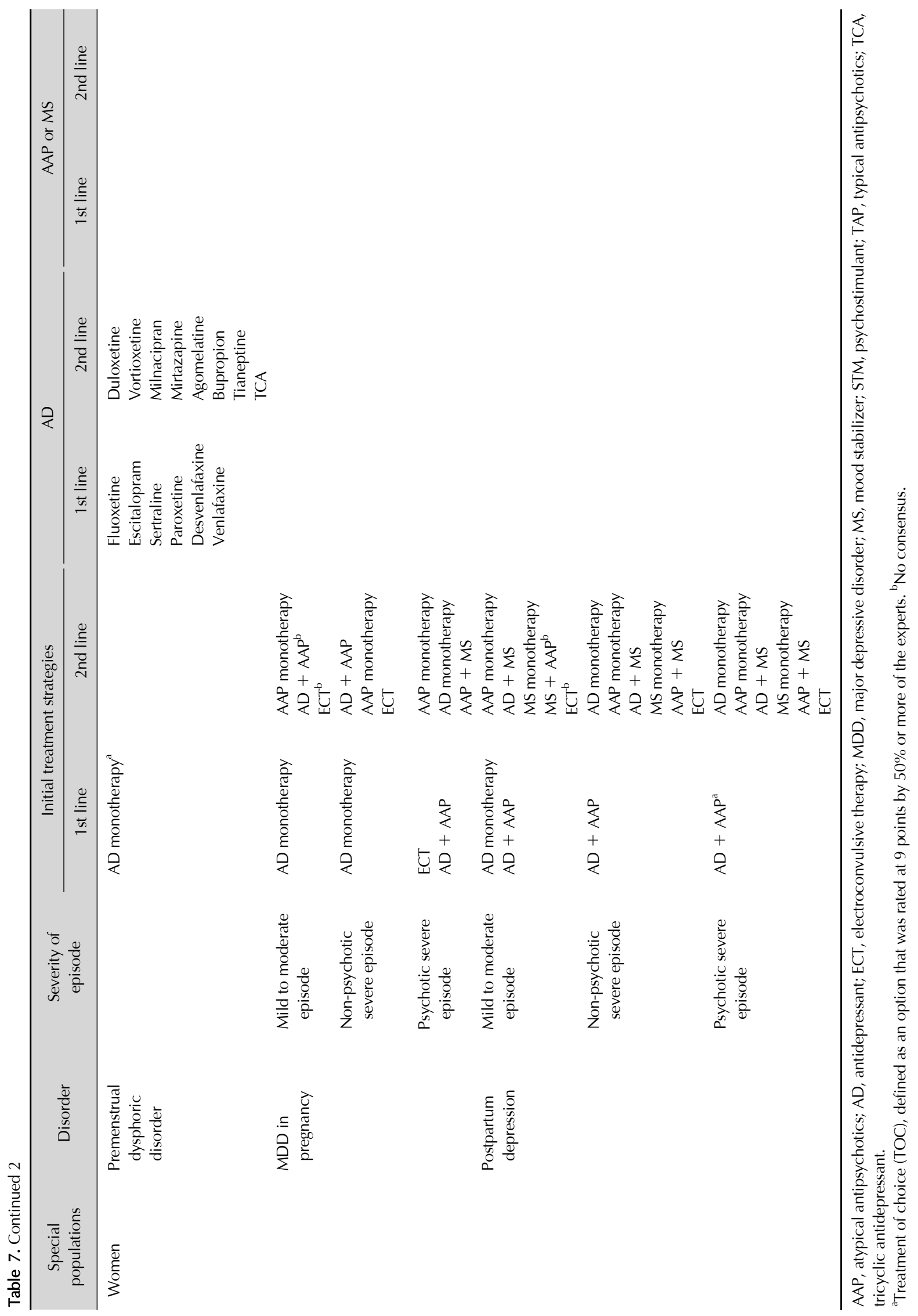


for premenstrual dysphoric disorder (PMDD). Fluoxetine, escitalopram, sertraline, paroxetine, desvenlafaxine, and venlafaxine were first-line ADs for PMDD. For MDD in pregnant women, $\mathrm{AD}$ monotherapy was recommended as the first-line treatment for mild-to-moderate and nonpsychotic severe depression. However, AD + AAP and ECT were recommended for psychotic severe depression. For postpartum depression, AD monotherapy and AD + AAP were the first-line strategies for mild-to-moderate episodes, and AD + AAP were recommended as the first-line treatment for non-psychotic severe episodes. For psychotic severe episodes, AD + AAP were the recommended TOC.

\section{Non-pharmacological Biological Treatment}

\section{Electroconvulsive therapy (ECT)}

Ninety-two percent of experts considered ECT to be an MDD treatment modality, and $43.8 \%$ of experts were applying it for MDD in clinical practice. On average, one expert conducts ECT with 7.0 persons per year, with 2.8 sessions per patient per week, totaling 10.5 sessions per patient during one treatment plan. The first-line indications for ECT were urgent suicidal risks in patients regardless of psychotic features and nonresponsiveness on pharmacotherapy with moderate episodes or severe episodes in pregnant patients.

\section{Indications for repetitive transcranial magnetic stimulation (rTMS)}

Eighty-nine percent of experts considered rTMS an MDD treatment option, but only $40.6 \%$ apply it in clinical practice for MDD. On average, one expert conducts rTMS with 12.6 persons per year, with 3.4 sessions per patient per week, totaling 12.6 sessions per patient during one treatment plan. In Korea, MDD in pregnant patients was the first-line indication for rTMS.

\section{Choice of complementary or novel agents}

Transcranial direct current stimulation (tDCS), vagus nerve stimulation (VNS), deep brain stimulation (BDS), light therapy, and omega-3 were considered as second-line treatment options for MDD.

\section{DISCUSSION}

Compared to KMAP-DD 2017, there are no significant changes in KMAP-DD 2021. However, we confirmed the increased preference of AAPs in various depressive conditions and the criteria for TRD that was first investigated in this revision and compared these results with previous versions of KMAP and foreign guidelines for depressive disorder [5-7].

\section{Treatment Strategies for Non-psychotic or Psychotic Depression}

\section{Initial step}

As a first step, the preferred initial treatment strategy for non-psychotic depressive episodes was AD monotherapy regardless of the severity of the depressive episodes, as recommended in KMAP-DD 2017, 2012, and 2006. Also, $\mathrm{AAP}+\mathrm{AD}$ combination as the first-line strategy for non-psychotic or psychotic severe depressive episodes was the same recommendation as in KMAP-DD 2017, while AD monotherapy was the only first-line strategy for non-psychotic severe episodes in KMAP-DD 2012, which implicated the increased preference of AAPs in Korea.

Foreign clinical guidelines recommended AD monotherapy instead of $\mathrm{AD}+\mathrm{AAP}$ combination as the first-line strategy for non-psychotic severe episodes on the bases of a benefit-harm comparison about initially using AAP for depression [5-8] and lack of evidence that AAP as an initial treatment strategy for depression is superior to $A D$ monotherapy [5].

However, given that the response rate of initial $A D$ monotherapy was $40-60 \%[9,10]$, the remission rate of initial AD monotherapy was $20-30 \%[11,12]$, and that a recent meta-analysis showed that the $\mathrm{AD}+\mathrm{AAP}$ combination is superior to $\mathrm{AD}$ monotherapy (response rate, odds ratio $[\mathrm{OR}]=1.69,95 \% \mathrm{Cl}=1.46-1.95, p<$ 0.00001 ; remission rates, $\mathrm{OR}=2.00,95 \% \mathrm{Cl}=1.69-$ 2.37, $p<0.00001$ ) [13], AD + AAP combination could also be a good choice as the first-line strategy for non-psychotic or psychotic severe depressive episodes.

The AD + AAP combination was recommended as the TOC for psychotic depression in KMAP-DD 2006, 2012, 2017, and 2021. Canadian Network for Mood and Anxiety Treatments (CANMAT) recommended AD + AAP for psychotic depression based on the finding that an 
$\mathrm{AD}+\mathrm{AAP}$ combination was superior to placebo 2 randomized controlled trials (RCTs), AD monotherapy (3 RCTs), and AAP monotherapy (4 RCTs) [5].

\section{Next step: Second and third steps}

As the next step after inadequate response to initial treatment, we should consider adding (combination or augmentation) or switching, after reevaluating the factors for the lack of response, such as inadequate dose, inadequate duration, and adherence. As the second step after an inadequate response to initial treatment, adding AD or AAP with a partial response and switching ongoing AD or AAP with no response to initial treatment is the same recommendation as in KMAP previous series and CANMAT 2016 [5]. Based on the most consistent evidence for efficacy of AAP in TRD, CANMAT recommended aripiprazole, quetiapine, and risperidone as adjunctive therapy with level I evidence [5].

\section{AD Choice}

\section{Preferred $A D$ as initial treatment}

For mild-to-moderate episodes, escitalopram was the only TOC in 2021, while escitalopram and sertraline were the TOCs in 2017. Escitalopram was the TOC for psychotic and non-psychotic severe depressive episodes in 2021 as well as in 2017 in contrast with the KMAP-DD 2012, in which there was no TOC among the ADs.

Although no single AD has proven to be more effective than others [6], Cipriani and colleagues, who conducted network analyses among 21 ADs, suggested that in head-to-head studies, agomelatine, amitriptyline, escitalopram, mirtazapine, paroxetine, venlafaxine, and vortioxetine were more effective than other antidepressants (range of ORs 1.19-1.96) [14]. Like these results, the preference of escitalopram for all severities of depressive episodes is the highest in Korea for more than 9 years.

The preference of vortioxetine, newly included in KMAP-DD 2021, for psychotic depression was as a second-line treatment in 2021. CANMAT 2016 recommended vortioxetine and agomelatine as well as SSRIs, SNRIs, bupropion, and mirtazapine as first-line [5]. But the preference of vortioxetine for psychotic depression was second-line in 2021. Also, the preference of agomelatine in Korea was second-line in KMAP-DD 2021 following 2017. This result reflects the Korean situation that agomelatine was first withdrawn in Korea in 2017 due to medical insurance issues with Korean government and then re-marketed in 2019. The preference of agomelatine has recently been increasing.

Esketamine (nasal spray), new and not yet widely used in Korea, was recommended as the second-line for nonpsychotic or psychotic severe episodes, which suggests higher expectations for this drug as an emergent drug as well as an AD by Korean experts. The US Food and Drug Administration (FDA) approved esketamine (nasal spray) for TRD $[15,16]$. A recent meta-analysis including 8 double-blinded, randomized controlled trials and 1,488 patients showed that esketamine significantly improved the Montgomery Asberg depression rating scale (MADRS) total score compared to placebo starting from 2-4 hours after the first administration (standardized mean difference, -0.41 [95\% Cl $=-0.58$ to -0.25$], p<0.00001$ ) [17], and this superiority was maintained until the end of the double-blinded period (28 days). Esketamine (nasal spray) has indication for suicidal ideation as well as TRD in Korea.

\section{$A D$ choice considering adverse effects, safety, and comorbid physical illness}

Due to a lack of evidence regarding this section, we mainly compare these results with previous KMAP-DD series. These results are almost the same in 2021, 2017, and 2012. When considering adverse effects, the following ADs were recommended with higher preference: 1) bupropion for sexual dysfunction, sleepiness or sedation, weight gain, safety accidents, serotonin syndrome, and orthostatic hypotension and 2) mirtazapine for insomnia, Gl trouble, and suicidal ideation.

A recent systemic review regarding $A D$ and weight gain showed that SSRIs including fluoxetine increase mean weight while bupropion decreases the mean weight [18]. Most experts in Korea would have the same clinical experience.

The clear mechanism for orthostatic hypotension in the elderly is unknown but due to its commonality [19], it can be assumed that bupropion was recommended as the first-line to take into consideration both orthostatic hypotension and anticholinergic side effects. However, CANMAT 2016 found patients taking bupropion-XL had more headache and dry mouth, by as much as $28 \%$ and $34 \%$, respectively, compared to other ADs. Therefore, careful 
prescription of bupropion is needed due to headache and dry mouth [5].

For suicidality, SSRIs are related to nearly twice the risk (OR 1.92) of suicide and suicidal attempts among adolescents in observational studies [20]. The US FDA warned that all antidepressants are related with an increase in suicidality among children and adolescents, including young adults (18-24 years), during initial treatment [21].

During the investigation period of KMAP-DD 2021, esketamine had only been approved for TRD in Korea. As a result, Korean experts recommended mirtazapine rather than esketamine when considering suicidality. However, a recent meta-analysis as described above showed that esketamine had superiority over placebo in TRD and suicidal ideation $(\mathrm{OR}=2.04,95 \% \mathrm{Cl}=1.37-3.05)$, but the groups did not statistically differ at 24 hours and day 28 [17]. With careful monitoring and assessment for suicidality at the beginning of $\mathrm{AD}$ treatment, particularly in children, adolescents, and young adults, esketamine is promising to protect against suicide.

When considering comorbid physical illness, escitalopram and sertraline were recommended as first- or second-line drugs for comorbidities of DM, thyroid disease, liver disease, renal disease, hypertension, seizure disorder, cardiovascular disease, cerebrovascular disease, parkinsonism, and arrhythmia. When choosing the initial $\mathrm{AD}$, after all, it is reasonable to select drugs by considering various factors including socioeconomic condition, safety issues, clinical experience, and comorbid physical conditions, as well as efficacy at the same time.

\section{AAP Choices}

For 15 years, there was a high preference of aripiprazole for non-psychotic severe episodes and aripiprazole, quetiapine, and olanzapine for psychotic severe episodes (Table 4). With level I evidence, foreign guidelines recommended aripiprazole, quetiapine, olanzapine, brexpiprazole, and lurasidone as adjunctive, not as AAP monotherapy $[5,6]$. That is, Korean experts recommend AAP as a first step, but foreign guidelines recommend AAP as the second step. Brexpiprazole and lurasidone are currently not available in Korea.

\section{Treatment Duration with the Initial AD before the Next Strategy (Switching to or Adding Another AD, etc.)}

We observed a shorter waiting duration between the in- itial and next-step treatment strategies, such as augmentation, switching, or combination. With no response to the initial treatment for mild-to-moderate depressive episodes, waiting durations were 3.3 - 6.1 weeks (2006), 3.2 7.5 weeks (2012), 2.9-6.4 weeks (2017), and 2.2-4.3 weeks (2021). With no response to the initial treatment for severe psychotic episodes, waiting durations were $2.4-$ 4.7 weeks (2012), 2.3 - 4.7 weeks (2017), and 1.7-3.3 weeks (2021). With a partial response to initial treatment for psychotic severe episodes, waiting durations were 3.46.9 weeks (2012), 3.4-6.5 weeks (2017), and 2.6-4.8 weeks (2021).

We observed a trend of shorter durations when there was no response than when there was a partial response to initial drugs, as was seen in previous KMAP series. This trend can also be seen in foreign guidelines. World Federation of Societies of Biological Psychiatry (WSFBP) 2017 [6] recommended that optimization be considered with an inadequate response to $\mathrm{AD}$ therapy for 2 weeks. In addition, CANMAT 2016 introduced 'early improvement', defined as $>20-30 \%$ reduction from baseline on a depression rating scale after $2-4$ weeks, as a predictor for later outcomes and prognoses and recommended increasing $\mathrm{AD}$ dosage or switching $\mathrm{AD}$ when intolerable at 2-4 weeks [5].

\section{Treatment Strategies for Persistent Depressive Disorder (dysthymia) and Strategies Specific to Subtype or Specifiers such as Mixed or Anxious Distress}

\section{Treatment strategies for PDD}

The recommendation for AD monotherapy as the initial strategy was the same as that of KMAP-DD 2021, 2017, 2012, and 2006. The preference of escitalopram as initial AD was the TOC in 2021 while a first-line treatment in 2017.

\section{Antidepressant choice according to subtypes}

\section{Melancholia}

Little information about the most effective agents for the melancholic and atypical subtypes is available [22]. Compared to the result of escitalopram and venlafaxine being TOCs in 2017, only escitalopram was the TOC in 2021. The preference of desvenlafaxine increased in 2021 compared to 2017. Recent Australian and New 
Zealand guidelines for major depression recommended venlafaxine and amitriptyline for melancholic types [22].

\section{Atypical features and seasonal patterns}

Mirtazapine was downgraded to a second-line treatment in 2021 after being a first-line treatment in 2017, which may reflect the selection of less sedative ADs considering atypical symptoms, such as hypersomnia and psychomotor retardation. Agomelatine was recommended as second-line in 2017 but was promoted to first-line in 2021, which seems to have considered the stimulation effect via blocking 5-HT2C of agomelatine and effect of improving hypersomnia through adjusting the sleep cycle [23].

For seasonal patterns, the first-line ADs in 2021 were the same as those recommended in 2017. These results were presumed to be a choice considering the (hypo)manic switching of seasonal patterns that can be related to bipolarity [24]; bupropion XR was approved for depressive patients with seasonal patterns in the US [25].

\section{Treatment strategies for anxious distress specifiers and} mixed feature (Table 5)

Preferred initial strategies for "with anxious distress" were AD + AAP or AD monotherapy both in 2017 and 2021. First-line ADs in 2017 were the same in 2021, except escitalopram was the TOC and vortioxetine was newly included as a first-line AD in 2021. Quetiapine was the only recommended first-line AAP for "with anxious distress' in 2017, but aripiprazole and olanzapine as well as quetiapine were the first-line AAPs in 2021. This showed that AAPs are not limited to psychosis or bipolar disorder but are also used for comorbid anxiety or agitation.

For mixed features, both KMAP-DD 2017 and 2021 had the same first-line strategies (AAP + AD and AD + $M S)$. Aripiprazole, quetiapine, olanzapine, valproate, and lithium were recommended as the first-line augmenting medications for mixed features. These recommended medications were consistent with previous trials [26] and similar to those for mixed state of bipolar disorder [27]. Despite the controversies about the criteria for mixed features in the Diagnostic and Statistical Manual of Mental Disorders, 5th edition (DSM-5) [28, 29], it is reasonable that mixed features in depressive episodes itself can be interpreted as bipolarity.

\section{The Consensus on the Definition of TRD}

There is no universal criteria or definition of TRD, but it is most commonly defined as at least two failures of $A D$ monotherapy with adequate dose, for 6-9 weeks during a major depressive episode [30]. We expected a similar answer from Korean experts; however, contrary to our expectation, among 6 questions, $44 \%$ of experts chose the criteria of TRD as "Failure to respond to two ADs + one AAP combination treatment". "Failure to respond to a two-AD combination treatment" was chosen the least, by $1.6 \%$ of experts.

"Treatment-resistance" can be defined when the treatment response is outside the boundaries of standard therapy. Of course, AAP is not literally an AD; however, a few AAPs demonstrated antidepressant efficacy in clinical trials with TRD [5,6], and CANMAT 2016 recommended quetiapine as one of the second-line ADs. Therefore, it is necessary to extend the criteria of TRD to include AAPs [5]. These results also demonstrated the Korean trend of using AAPs in an earlier step in treating depression, with increased preference for AAPs.

\section{Treatment Strategies for Special Populations (Table 7)}

Because it is ethically difficult to conduct RCTs with special populations, such as children, pregnant subjects, and elderly subjects with depression, experts' consensus could be useful. However, experts' experience is not always right, as evidence is not always right. Special populations with depression should be carefully treated according to an advantage-disadvantage evaluation.

\section{Treatment strategy for children and adolescents}

\section{Disruptive mood dysregulation disorder (DMDD)}

This section has been included since KMAP-2012. In this revision, more detailed results could be obtained by distinguishing between children (5 to 12 years old) and adolescents (13 to 17 years old) in MDD, except for disruptive mood dysregulation disorder (DMDD).

The prevalence of DMDD, newly introduced in DSM-5, among children and adolescents has been as much as $2-5 \%$ [31,32]; however, there was no first-line strategy for DMDD in KMAP-DD 2021. Korean experts cautiously recommended AAP monotherapy, AD + AAP, and $\mathrm{AD}$ monotherapy as a second-line treatment. Given that two key symptoms are severe recurrent temper out- 
bursts and persistent irritability observable by others, a higher preference for AAPs rather than ADs was reasonable, although DMDD is a type of depressive disorder.

Among AAPs, aripiprazole was the TOC for DMDD. Preference for risperidone was increased to a first-line drug in 2021 after being a second-line drug in 2017. These changes are consistent with results on tic disorder in Korea: aripiprazole was preferred over risperidone in terms of side effects [33], and results of the effects of AAP on DMDD demonstrated the efficacy of risperidone [31,32].

Considering the risks associated with valproate for pregnant women [34, 35], experts were asked to consider their choice of mood stabilizer differently between male and female patients. Valproate was the first-line treatment for DMDD in men but a second-line treatment for DMDD in women.

\section{Children and adolescents with major depression}

Similar to the recommendations of KMAP-DD 2017 and 2012, AD monotherapy was recommended as the TOC for mild-to-moderate episodes in children and the first-line strategy for mild-to-moderate episodes in adolescents. AD monotherapy and AD + AAP combination were the first-line strategies for non-psychotic severe depression in children and adolescents, and AD + AAP was the TOC for psychotic severe depression in children and adolescents, which was the same as in KMAP-DD 2017.

Aripiprazole was the TOC and risperidone and quetiapine were the first-line treatments for psychotic severe depression in children and adolescents in 2021, while aripiprazole and risperidone were the first-line treatments in 2017. However, AAPs were not included in the treatment strategy of CANMAT 2016 for child/adolescent depression [36].

Caution should be paid to AD use in children and adolescents, because ADs may be associated with increased risk of suicide in adolescents [36] and with (hypo)manic switching in young patients with bipolarity [37]. As the first-line AD for children and adolescents with MDD, escitalopram, fluoxetine, and sertraline were recommended. A recent Cochrane review of 19 trials with subjects aged 6 18 years ( $n=3,335$ ) showed that fluoxetine was significantly more effective than placebo, and sertraline was also significantly effective with a small effect size [38]. CANMAT 2016 recommended fluoxetine rather than es- citalopram as the second step after initial cognitive-behavioral therapy (CBT) or interpersonal therapy (IPT) and internet-based psychotherapy [36], while the preference for escitalopram seems to be higher than that of fluoxetine in Korea. It can be seen as a result of considering the superior efficacy of escitalopram on improving children and adolescents' function and symptoms compared to placebo [38-40], its effect during maintenance treatment [41], and favorable safety issues including drug-drug interactions via CYP450 2D6, 3A4 [42].

By risk-benefit evaluation, psychosocial intervention was recommended as the first step for mild depressive episodes in children/adolescents, but for more severe episodes or when initial psychosocial intervention for mild depressive episodes failed in children and adolescent, pharmacotherapy could be recommended as the first step [36].

\section{Treatment strategy for elderly adults}

According to big data analysis from the Korea Health Insurance Review and Assessment Service (HIRA), the number of patients treated for depression increased from 588,000 in 2014 to 681,000 in 2017, and among the $684,690$ patients treated in $2018,40 \%$ ( $n=275,684)$ of them were over the age of 60 [43]. Unlike typical middle-aged depression, memory loss, fatigue, loss of appetite, insomnia, and pain, rather than depressed mood, are more common in elderly depression [44].

The recommendations for the first-line treatment strategies for each severity of episode in 2021 were the same as those in 2017: AD monotherapy for mild-to-moderate depressive episodes as TOC, AD + AAP and AD monotherapy for non-psychotic severe depression, and an AD + AAP combination for psychotic severe episodes.

Compared to KMAP-DD 2017, the preference of aripiprazole increased from first-line to the TOC in 2021. Adjunctive aripiprazole with various ADs [45] and aripiprazole augmentation for treatment-resistant depression was found to be effective for elderly depression [46]. Considering diabetes, hypertension, metabolic syndrome, the anticholinergic effect, and somnolence, aripiprazole was more highly preferred than other AAPs [47].

Due to lack of evidence for escitalopram, CANMAT [36] recommended duloxetine, mirtazapine, and nortriptyline instead of escitalopram as first-line ADs with level I evidence, while escitalopram was considered to be 
the preferred AD by many clinicians including the Korean experts $[48,49]$.

Despite clinical limitations in treating elderly depression, it is clear that certain factors, such as comorbid physical illnesses, drug-drug interaction, and decreased metabolism due to the aging effect, should be considered in treating depression in the elderly.

\section{Treatment strategy for women with premenstrual dysphoric disorder or postpartum depression}

According to HIRA data survey, among the 681,000 depressed patients in Korea in 2017, there were 450,000 female patients, twice as many as the males [43]. As in KMAP-DD 2012 and 2017, AD monotherapy was recommended as the TOC for PMDD; in particular, escitalopram was the TOC for PMDD in 2017, while fluoxetine, escitalopram, sertraline, paroxetine, desvenlafaxine, and venlafaxine were the recommended first-line drugs. That is, the preference for SSRIs is higher than for other ADs in treating PMDD, which is consistent with foreign research [50-52].

In treating pregnant women, as with older people and children and adolescents, we should evaluate the benefit-risk ratio. CANMAT 2016 recommends escitalopram and sertraline after initially applying CBT and IPT for mild-to-moderate major depressive disorder during pregnancy with level I evidence, but recommends pharmacotherapy alone or combined with CBT or IPT for severe depression during pregnancy [36]. The fact that $\mathrm{AD}$ monotherapy was recommended for mild-to-moderate and non-psychotic severe episodes while ECT or AD + AAP was recommended for psychotic severe episodes, in KMAP-DD 2021 reflects a careful choice of treatment strategies as in CANMAT 2016.

Changes in the recommendations for postpartum depression were that $A D$ monotherapy was the TOC for mild-to-moderate episodes in 2017, while AD + AAP as well as $\mathrm{AD}$ monotherapy were the first-line strategies in 2021. In addition, an AD + AAP combination was recommended as first-line for severe episodes with/without psychotic features as in the previous version. For postpartum depression, CANMAT 2016 also recommends CBT and IPT as first-line and escitalopram and sertraline as second-line [36].

\section{Non-pharmacological Biological Therapy}

\section{ECT, rTMS}

ECT for non-psychotic severe MDD with self-harm or suicidal risk regardless of psychotic features and TMS for pregnant women were recommended as first-line. Most Korean experts consider ECT (92\% in 2021 vs. $92.4 \%$ in 2017) and rTMS (89\% in 2021 vs. $86.0 \%$ in 2017) to be good treatment strategies in line with recent evidence [53,54]. Compared to $44.3 \%$ in $2017,43.8 \%$ of experts conduct ECT in 2021, while compared to $31.6 \%$ in 2017, $40.6 \%$ in 2021 have used rTMS in real practice.

For the treatment of MDD, CANMAT 2016 recommended ECT as a second-line treatment, and rTMS for patients who have had failed treatment, based on efficacy, tolerability, and safety, with at least $1 \mathrm{AD}$ as a first-line treatment [55]. As with previous revisions, the executive committee recommended that ECT could be applied whenever depressed patients have potential suicidality or attempt at self-harm.

\section{Alternative biological therapies}

In Korea, these alternative therapies are less popular than ECT or rTMS. As second-line treatment strategies, the frequencies of use in 2021 of light therapy, omega- 3 nutritional therapy, and tDCS combined with initial pharmacotherapy, which are complementary or novel agents, were $17.2 \%$ (vs. $27.8 \%$ in 2017 ), $18.8 \%$ (vs. $22.8 \%$ in 2017), and $7.8 \%$, respectively, which currently indicates a low utilization rate. CANMAT 2016 recommended light therapy alone as a first-line treatment for seasonal MDD and as a second-line treatment for non-seasonal, mild-tomoderate MDD [51]. Although tDCS is less effective for TRD, the onset of its effect was faster than AD monotherapy with equal efficacy [56], and when adjuvant with $A D$, its efficacy was superior to AD monotherapy [57], and it is a relatively safe, non-invasive modality that can improve cognition in MDD patients [58,59].

\section{Summary: Advantages and Limitations of KMAP-DD 2021}

A main limitation is the characteristics of the experts' consensus guidelines. As stated in another paper [3], experts' consensus and evidence-based guidelines are not contradictory, but complementary. To do this, the executive committee published final guidelines through the 
process of drawing opinions from experts and reviewing the results with clinical evidence.

Second, the review committee may have been too small $(n=94)$ to reach a valid consensus and to select a TOC. However, given that there are only 3,800 psychiatrists in Korea and given that the total lifelong membership of the KSAD is only 258, a sample of 94 psychiatrists may be not insufficient. Finally, we did not explore psychosocial approaches, which should be addressed in a future study.

In summary, a shortened waiting time between the initial and subsequent treatments, increased preference for AAPs, especially aripiprazole, and combination strategies with AAPs yield an active and somewhat aggressive treatment trend in Korea. To our knowledge, the KMAP-DD series is the only experts' consensus guideline in the world that has been updated and revised at regular intervals since 2002. Reminding one of the principles of KMAP development that this guideline cannot go beyond the physicians' clinical decision, we expect KMAP-DD to provide clinicians with useful information about the specific strategies and medications appropriate for treating patients with MDD by bridging the gap between clinical real practice and evidence-based world.

\section{Acknowledgments}

The present manuscript is a secondary publication of our group's papers, which were already published in the Korean language.

Though we have already published the papers in Korea, we decided to present and share the results with Englishspeaking experts according to the conditions for acceptable secondary publications as stated in Uniform Requirements for Manuscripts Submitted to Biomedical Journals by the International Committee of Medical Journal Editors.

This study was supported by the Korean Society for Affective Disorders and the Korean College of Neuropsychopharmacology. This research did not receive any specific grant from funding agencies in the commercial sector.

\section{- Conflicts of Interest}

No potential conflict of interest relevant to this article was reported.

\section{Author Contributions}

Conceptualization: Jeong Seok Seo, Won-Myong Bahk. Study design and data collection: Jeong Seok Seo, Won-Myong Bahk, Young Sup Woo, Young-Min Park, Won Kim, Jong-Hyun Jeong, Se-Hoon Shim, Jung Goo Lee, Seung-Ho Jang, Chan-Mo Yang, Sheng-Min Wang, Myung Hun Jung, Hyung Mo Sung, IL Han Choo, Bo-Hyun Yoon, Sang-Yeol Lee, Duk-In Jon, Kyung Joon Min. Data analysis and interpretation: Jeong Seok Seo, Won-Myong Bahk, Young Sup Woo, Young-Min Park, Won Kim, Jong-Hyun Jeong, Se-Hoon Shim, Jung Goo Lee. Funding acquisition: Won-Myong Bahk, Jeong Seok Seo. Draft manuscript preparation: Jeong Seok Seo. All authors reviewed the results and approved the final version of the manuscript.

\section{ORCID}

Jeong Seok Seo https://orcid.org/0000-0002-4880-3684 Won-Myong Bahk https://orcid.org/0000-0002-0156-2510 Young Sup Woo https://orcid.org/0000-0002-0961-838X Young-Min Park https://orcid.org/0000-0002-4993-1426 Won Kim https://orcid.org/0000-0002-5478-7350 Jong-Hyun Jeong https://orcid.org/0000-0003-3570-7607 Se-Hoon Shim https://orcid.org/0000-0002-3137-6591 Jung Goo Lee https://orcid.org/0000-0003-3393-2667 Seung-Ho Jang https://orcid.org/0000-0002-3479-0552 Chan-Mo Yang https://orcid.org/0000-0002-4959-7595 Sheng-Min Wang https://orcid.org/0000-0003-2521-1413 Myung Hun Jung https://orcid.org/0000-0003-2393-3930 Hyung Mo Sung https://orcid.org/0000-0002-2396-3358 IL Han Choo https://orcid.org/0000-0001-6547-9735 Bo-Hyun Yoon https://orcid.org/0000-0002-3882-7930 Sang-Yeol Lee https://orcid.org/0000-0003-1828-9992 Duk-In Jon https://orcid.org/0000-0002-1565-7940 Kyung Joon Min https://orcid.org/0000-0001-7037-8904

\section{REFERENCES}

1. Lee MS, Lim SW, Cha JH, Chung SK, Kim KS, Kasper S; The Executive Committee for the Korean Medication Algorithm Project for Major Depressive Disorder. The Korean Medication Algorithm for Major Depressive Disorder (KMA-MDD): report of the Korean Society of Depressive and Bipolar Disorders. Int I Psychiatry Clin Pract 2006;10:186-194.

2. Seo JS, Min KJ, Kim W, Seok JH, Bahk WM, Song HC, et al. Korean Medication Algorithm for Depressive Disorder 2006 (I). J Korean Neuropsychiatr Assoc 2007:46:453-460. 
3. Seo JS, Song HR, Lee HB, Park YM, Hong JW, Kim W, et al. The Korean Medication Algorithm for Depressive Disorder: second revision. J Affect Disord 2014;167:312-321.

4. Seo JS, Bahk WM, Wang HR, Woo YS, Park YM, Jeong JH, et al. Korean Medication Algorithm for Depressive Disorders 2017: third revision. Clin Psychopharmacol Neurosci 2018; 16:67-87.

5. Kennedy SH, Lam RW, McIntyre RS, Tourjman SV, Bhat V, Blier P, et al. Canadian Network for Mood and Anxiety Treatments (CANMAT) 2016 clinical guidelines for the management of adults with major depressive disorder: section 3. Pharmacological treatments. Can J Psychiatry 2016;61:540560.

6. Bauer M, Severus E, Möller HJ, Young AH; WFSBP Task Force on Unipolar Depressive Disorders. Pharmacological treatment of unipolar depressive disorders: summary of WFSBP guidelines. Int J Psychiatry Clin Pract 2017;21:166-176.

7. Cleare A, Pariante CM, Young AH, Anderson IM, Christmas D, Cowen PJ, et al. Evidence-based guidelines for treating depressive disorders with antidepressants: a revision of the 2008 British Association for Psychopharmacology guidelines. J Psychopharmacol 2015;29:459-525.

8. Spielmans Gl, Berman MI, Linardatos E, Rosenlicht NZ, Perry A, Tsai AC. Adjunctive atypical antipsychotic treatment for major depressive disorder: a meta-analysis of depression, quality of life, and safety outcomes. PLoS Med 2013;10:e1001403.

9. Schulberg HC, Katon W, Simon GE, Rush AJ. Treating major depression in primary care practice: an update of the Agency for Health Care Policy and Research Practice Guidelines. Arch Gen Psychiatry 1998;55:1121-1127.

10. Williams JW Jr, Mulrow CD, Chiquette E, Noël PH, Aguilar C, Cornell J. A systematic review of newer pharmacotherapies for depression in adults: evidence report summary. Ann Intern Med 2000;132:743-756.

11. Fava M, Rush AJ, Trivedi MH, Nierenberg AA, Thase ME, Sackeim HA, et al. Background and rationale for the sequenced treatment alternatives to relieve depression (STAR*D) study. Psychiatr Clin North Am 2003;26:457-494, x.

12. Fava M, Davidson KG. Definition and epidemiology of treatment-resistant depression. Psychiatr Clin North Am 1996;19. 179-200.

13. Nelson JC, Papakostas GI. Atypical antipsychotic augmentation in major depressive disorder: a meta-analysis of placebocontrolled randomized trials. Am J Psychiatry 2009;166:980991.

14. Cipriani A, Furukawa TA, Salanti G, Chaimani A, Atkinson LZ, Ogawa Y, et al. Comparative efficacy and acceptability of 21 antidepressant drugs for the acute treatment of adults with major depressive disorder: a systematic review and network meta-analysis. Lancet 2018;391:1357-1366.

15. U.S. Food and Drug Administration.Drugs@FDA: FDA-approved drugs [Internet]. Silver Spring: U.S. Food and Drug Administration [cited at 2019 May 9]. Available from: https://www.accessdata.fda.gov/drugsatfda_docs/label/2019/ 211243s001/bl.pdf.

16. U.S. Food and Drug Administration. FDA approves new nasal spray medication for treatment-resistant depression; available only at a certified doctor's office or clinic [Internet]. Silver Spring: U.S. Food and Drug Administration [cited at 2019 May 3]. Available from: https://uww.fda.gov/news-events/press-announcements/fda-approves-new-nasal-spray-medication-treatment-resistant-depression-available-only-certified.

17. Wang SM, Kim NY, Na HR, Lim HK, Woo YS, Pae CU, et al. Rapid onset of intranasal esketamine in patients with treatment resistant depression and major depression with suicide ideation: a meta-analysis. Clin Psychopharmacol Neurosci 2021:19:341-354.

18. Alonso-Pedrero L, Bes-Rastrollo M, Marti A. Effects of antidepressant and antipsychotic use on weight gain: a systematic review. Obes Rev 2019;20:1680-1690.

19. Pollock BG. Adverse reactions of antidepressants in elderly patients. J Clin Psychiatry 1999;60 Suppl 20:4-8.

20. Barbui C, Esposito E, Cipriani A. Selective serotonin reuptake inhibitors and risk of suicide: a systematic review of observational studies. CMA 2009;180:291-297.

21. Freeman RA. Antidepressants' black-box warning - 10 years later. N Eng/ J Med 2014;371:1666-1668.

22. Malhi GS, Bell E, Singh AB, Bassett D, Berk M, Boyce $P$, et al. The 2020 Royal Australian and New Zealand College of Psychiatrists clinical practice guidelines for mood disorders: major depression summary. Bipolar Disord 2020;22:788-804.

23. Norman TR, Olver JS. Agomelatine for depression: expanding the horizons? Expert Opin Pharmacother 2019;20:647-656.

24. Sohn CH, Lam RW. Treatment of seasonal affective disorder: unipolar versus bipolar differences. Curr Psychiatry Rep 2004; 6:478-485.

25. Galima SV, Vogel SR, Kowalski AW. Seasonal affective disorder: common questions and answers. Am Fam Physician 2020;102:668-672.

26. Han C, Wang SM, Bahk WM, Lee SJ, Patkar AA, Masand PS, et al. The potential utility of aripiprazole augmentation for major depressive disorder with mixed features specifier: a retrospective study. Clin Psychopharmacol Neurosci 2019;17: 495-502.

27. Jeong JH, Bahk WM, Woo YS, Lee JG, Kim MD, Sohn I, et al. Korean Medication Algorithm for Bipolar Disorder 2018: comparisons with other treatment guidelines. Clin Psychopharmacol Neurosci 2019;17:155-169.

28. Park YM. The mixed-features specifier of major depressive disorder in DSM-5: is it practical? Psychiatry Investig 2018;15: 1009-1010.

29. Koukopoulos A, Sani G, Ghaemi SN. Mixed features of depression: why DSM-5 is wrong (and so was DSM-IV). Br J Psychiatry 2013;203:3-5.

30. $\mathrm{Ng} \mathrm{CH}$, Kato T, Han C, Wang G, Trivedi M, Ramesh $\mathrm{V}$, et al. Definition of treatment-resistant depression - Asia Pacific 
perspectives. J Affect Disord 2019;245:626-636

31. Baweja R, Mayes SD, Hameed U, Waxmonsky JG. Disruptive mood dysregulation disorder: current insights. Neuropsychiatr Dis Treat 2016;12:2115-2124.

32. American Psychiatric Association. Diagnostic and statistical manual of mental disorders. 5th ed. Virginia:American Psychiatric Association;2013.

33. Yoo HK, Lee JS, Paik KW, Choi SH, Yoon SJ, Kim JE, et al. Open-label study comparing the efficacy and tolerability of aripiprazole and haloperidol in the treatment of pediatric tic disorders. Eur Child Adolesc Psychiatry 2011,20:127-135.

34. Tomson T, Battino D, Bonizzoni E, Craig J, Lindhout D, Sabers $\mathrm{A}$, et al. Dose-dependent risk of malformations with antiepileptic drugs: an analysis of data from the EURAP epilepsy and pregnancy registry. Lancet Neurol 2011;10:609-617.

35. Meador K, Reynolds MW, Crean S, Fahrbach K, Probst C. Pregnancy outcomes in women with epilepsy: a systematic review and meta-analysis of published pregnancy registries and cohorts. Epilepsy Res 2008;81:1-13.

36. MacQueen GM, Frey BN, Ismail Z, Jaworska N, Steiner M, Lieshout RJ, et al. Canadian Network for Mood and Anxiety Treatments (CANMAT) 2016 clinical guidelines for the management of adults with major depressive disorder: section 6. Special populations: youth, women, and the elderly. Can J Psychiatry 2016;61:588-603.

37. Ghaemi SN, Ko JY, Goodwin FK. “Cade's disease” and beyond: misdiagnosis, antidepressant use, and a proposed definition for bipolar spectrum disorder. Can I Psychiatry 2002; 47:125-134.

38. Hetrick SE, McKenzie JE, Cox GR, Simmons MB, Merry SN. Newer generation antidepressants for depressive disorders in children and adolescents. Cochrane Database Syst Rev 2012; 11:CD004851.

39. Wagner KD, Jonas J, Findling RL, Ventura D, Saikali K. A double-blind, randomized, placebo-controlled trial of escitalopram in the treatment of pediatric depression. I Am Acad Child Adolesc Psychiatry 2006:45:280-288.

40. Cipriani A, Zhou X, Del Giovane C, Hetrick SE, Qin B, Whittington $\mathrm{C}$, et al. Comparative efficacy and tolerability of antidepressants for major depressive disorder in children and adolescents: a network meta-analysis. Lancet 2016;388:881890.

41. Findling RL, Robb A, Bose A. Escitalopram in the treatment of adolescent depression: a randomized, double-blind, placebocontrolled extension trial. J Child Adolesc Psychopharmacol 2013;23:468-480.

42. Stahl SM. Stahl's essential psychopharmacology: neuroscientific basis and practical application. 4th ed. Cambridge:Cambridge University Press;2013. p. 48-51.

43. Korea Social Security Information Service. Last year, 450,000 women suffered from depression $\cdots$ twice that of men [Internet]. Seoul: Korea Social Security Information Service; 2018. Available from: https://www.bokjiro.go.kr/nwel/welfareinfo/livwelnews/
news/retirevelssueDetail.do?dataSid $=6634143$.

44. Jung YE, Kim MD, Bahk WM, Woo YS, Nam B, Seo JS, et al. Validation of the Korean version of the depression in old age scale and comparison with other depression screening questionnaires used in elderly patients in medical settings. Clin Psychopharmacol Neurosci 2019;17:369-376.

45. Steffens DC, Nelson JC, Eudicone JM, Andersson C, Yang H, Tran QV, et al. Efficacy and safety of adjunctive aripiprazole in major depressive disorder in older patients: a pooled subpopulation analysis. Int J Geriatr Psychiatry 2011;26:564-572.

46. Lenze EJ, Mulsant BH, Blumberger DM, Karp JF, Newcomer JW, Anderson SJ, et al. Efficacy, safety, and tolerability of augmentation pharmacotherapy with aripiprazole for treatment-resistant depression in late life: a randomised, double-blind, placebo-controlled trial. Lancet 2015;386:24042412.

47. Cakir S, Senkal Z. Atypical antipsychotics as add-on treatment in late-life depression. Clin Interv Aging 2016;11:1193-1198.

48. Mulsant BH, Blumberger DM, Ismail Z, Rabheru K, Rapoport MJ. A systematic approach to pharmacotherapy for geriatric major depression. Clin Geriatr Med 2014;30:517-534.

49. Canadian Coalition for Seniors' Mental Health. National guidelines for seniors' mental health-the assessment and treatment of depression [Internet]. Toronto: Canadian Coalition for Seniors' Mental Health; 2006 [cited at 2006 May]. Available from: https:// ccsmh.ca/wp-content/uploads/2016/03/Nat/Guideline_LTC.pdf.

50. Sachs GS, Printz DJ, Kahn DA, Carpenter D, Docherty JP. The expert consensus guideline series: medication treatment of bipolar disorder 2000. Postgrad Med 2000;Spec No:1-104.

51. Hofmeister S, Bodden S. Premenstrual syndrome and premenstrual dysphoric disorder. Am Fam Physician 2016;94:236240.

52. Lanza di Scalea T, Pearlstein T. Premenstrual dysphoric disorder. Med Clin North Am 2019;103:613-628.

53. Kar SK. Predictors of response to repetitive transcranial magnetic stimulation in depression: a review of recent updates. Clin Psychopharmacol Neurosci 2019;17:25-33.

54. Chou PH, Lin YF, Lu MK, Chang HA, Chu CS, Chang WH, et al. Personalization of repetitive transcranial magnetic stimulation for the treatment of major depressive disorder according to the existing psychiatric comorbidity. Clin Psychopharmacol Neurosci 2021;19:190-205.

55. Milev RV, Giacobbe P, Kennedy SH, Blumberger DM, Daskalakis ZJ, Downar J, et al. Canadian Network for Mood and Anxiety Treatments (CANMAT) 2016 clinical guidelines for the management of adults with major depressive disorder: section 4. Neurostimulation treatments. Can J Psychiatry 2016; 61:561-575.

56. Rigonatti SP, Boggio PS, Myczkowski ML, Otta E, Fiquer JT, Ribeiro RB, et al. Transcranial direct stimulation and fluoxetine for the treatment of depression. Eur Psychiatry 2008;23: 74-76.

57. Brunoni AR, Valiengo L, Baccaro A, Zanão TA, de Oliveira JF, 
Goulart A, et al. The sertraline vs. electrical current therapy for treating depression clinical study: results from a factorial, randomized, controlled trial. JAMA Psychiatry 2013;70:383391.

58. Oliveira JF, Zanão TA, Valiengo L, Lotufo PA, Benseñor IM, Fregni $\mathrm{F}$, et al. Acute working memory improvement after $t D C S$ in antidepressant-free patients with major depressive disorder. Neurosci Lett 2013;537:60-64.

59. Brunoni AR, Zanao TA, Vanderhasselt MA, Valiengo L, de Oliveira JF, Boggio PS, et al. Enhancement of affective processing induced by bifrontal transcranial direct current stimulation in patients with major depression. Neuromodulation 2014;17:138-142. 